Preprints of the

Max Planck Institute for

Research on Collective Goods

Bonn 2011/24

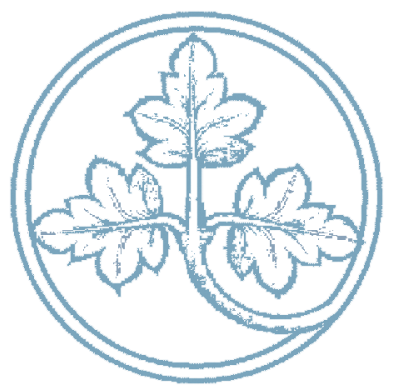

The State's Enforcement

Monopoly and the Private

Protection of Property

Kristoffel Grechenig

Martin Kolmar

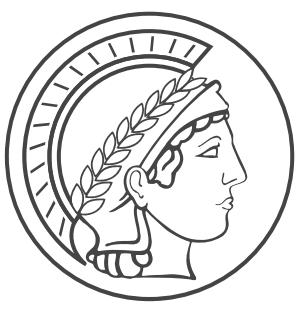




\section{The State's Enforcement Monopoly and the Private Protection of Property}

Kristoffel Grechenig / Martin Kolmar

September 2011 


\title{
The State's Enforcement Monopoly and the Private Protection of Property
}

\author{
Kristoffel Grechenig $\quad$ Martin Kolmar*
}

September 29, 2011

${ }^{*}$ Grechenig: Max Planck Institute for Research on Collective Goods, Kurt-Schumacher-Str. 10, 53113 Bonn, Germany, email: grechenig@coll.mpg.de. Kolmar: Institute of Economics, University of St. Gallen, Varnbüelstrasse 19, CH-9000 St. Gallen, email: martin.kolmar@unisg.ch. We thank Philipp Denter, Dana Sisak, Christoph Engel, and the participants of the Ratio Group at the MPI for Research on Collective Goods, Bonn, for valuable comments and discussions. 


\begin{abstract}
The modern state has monopolized the legitimate use of force. This concept is twofold. First, the state is empowered with enforcement rights; second, the rights of the individuals are (partly) restricted. In a simple model of property rights with appropriation and defense activity, we show that a restriction of private enforcement is beneficial for the property owner, even if there are no economies of scale from public protection. We emphasize the role of the state as a commitment device for a certain level of enforcement. However, commitment will only work if the state can regulate private protection. A ban of private enforcement measures can even be beneficial in situations where there would be no private enforcement at first place because the "shadow" of defense has a negative impact on the investments in property rights infringements. From a legal perspective, our approach emphasizes a regulation of victim behavior as opposed to the standard approach which focuses on the regulation of criminal behavior.
\end{abstract}

Keywords: Property Rights, Enforcement, Private Protection, Law, Contests JEL classifications: K42, P14, P37, P48, N40 


\section{Introduction}

So the nature of War, consisteth not in actuall fighting; but in the known disposition thereto Hobbes, Leviathan, Chapter 13

The modern state has monopolized the legitimate use of force (Weber, 1919). It protects the property rights of the people and it limits private enforcement. Weber's concept of the monopoly on the use of force has been important in philosophy of law and political philosophy despite the fact that - or maybe exactly because - the original statement of the principle has a rather shimmering meaning between a positive observation and a normative claim. Most scholars seem to agree that it can be meaningfully interpreted as a normative principle that allocates the authority to justify physical violence to the state. In the tradition of Thomas Hobbes $(1642,1651)$, the state's monopoly can be thought of as being based on a social contract and it is necessary to prevent a war of everyone against everyone (bellum omnium contra omnes), but alternative concepts of a social contract also fit into this line of argumentation.

In the Early Middle-Ages, feuds paired with theft and robbery were a major concern in Europe, leading to several attempts to restore peace through the laws of "Landfrieden". The first step was to declare theft to be illegal, i.e., to assign formal property rights and to sanction violations. However, this was not enough for a peaceful environment to emerge. An important restriction was to limit private enforcement which included punishment and self-justice (Kaufmann 1978). According to today's understanding of the state's enforcement monopoly, it is also an important feature that punishment and retribution are not in the hands of individuals. However, the state's monopoly goes further and includes a prohibition of violence more generally.

Feuds were not only an expression of self-justice, but they were closely connected to the protection of property and repossession of goods. Oftentimes, feuds were allowed only if a right could not be legally enforced. Attempts of legal enforcement failed in the Middle-Ages due to the lack of a strong centralized authority. As a consequence, a great part of the resources were used for appropriation and defense, not for production. From an economic perspective, the main role of restricting feuds may have been to divert resources from conflicts to productive activity. Consequently, prohibitions were extended to investments in potential conflicts, not only to conflicts as such. For example, the law 
of 1152 by Friedrich I included a prohibition of weapons for farmers, the Bavarian law of 1244 prohibited carrying concealed knives (Holzhauer 1978).

Weber does not exclude that the actual application of violence can be delegated to individuals in defense of one's self or property, which - bringing the statement close to a tautology without a theory of centralized versus decentralized law enforcement - gives the principle more the character of a paradigmatic statement about the nature of the state. We can therefore distinguish between two conceptual views of the concept of a monopoly of force, one referring to the legitimization to the use of (physical) violence without reference to the actual execution of rights enforcement, and the other refering to this latter aspect of the execution or production of rights. We call the two views 'legitimization' and 'production' of law enforcement, and it is exactly this latter view that has been mostly neglected in the literature so far, despite its obvious importance for the evaluation of institutional arrangements of law enforcement in practice.

To give an example, the delegation of private enforcement to the government is a highly disputed issue when it comes to the private possession of firearms. The legal debate circulated around the question whether the Second Amendment to the United States Constitution protected an individual right to carry guns. Generally, U.S. state laws restricted the individual right to carry guns and many believed that states in fact had a wide discretion to do so. Even with these laws in place, the United States was much less restrictive towards its citizens than European countries which widely prohibit the private possession of guns. Wimmer (2003) brings this contrast to the point: "Whereas the European state had been quite successful in its history in forbidding the (private) ownership of weapons or to carry arms (openly), that is, in its attempt to disarm its populations, in the United States exactly this has not been the case [...]." The United States' approach has recently been strengthened through two decisions by the Supreme Court. In 2008 and 2010, the Supreme Court held that the Second Amendment protected an individual right which could not be limited by state and federal laws unless there was a clear justification (District of Columbia v. Heller, 2008, McDonald v. City of Chicago, 2010). As a consequence, some state legislation was declared unconstitutional, including a law that restricted the possession of firearms by ex-felons (Britt v. North Carolina, 2009). Other state laws that restricted the private use of guns were upheld, including laws that restricted the unlicensed possession of firearms (People v. Perkins, 2009, Hamblen v. U.S., 2009), guns with obliterated serial numbers (U.S. v. Marzzarella 2009), juvenile possession (U.S. v. Rene, 2009). How much discretion federal and state legislators have remains 
unclear (Levy, 2010, Bone, 2010, Volokh, 2009). Apart from the doctrinal legal discussion (Rosenthal, Malcolm, 2010), many scholars have advanced economic arguments for and against gun control (Donohue, 2004).

The discussion on the delegation of powers has a lot of aspects, including whether Weber's view with respect to the legitimization of law enforcement is appropriate for a state with a potential of a democracy to turn into a tyranny. There are good reasons to take the problem of abusing power seriously because history is full of examples of states whose leaders could - to paraphrase Oscar Wilde - resist everything except the temptation to turn their power against their own citizens. ${ }^{1}$ However, in this paper we focus attention on the role of limitations of private measures of law enforcement like private armies and gun control laws for the efficiency of (property) rights enforcement. This should provide us with a better understanding of whether the legitimization view of Weber's principle leverages onto an efficiency argument supporting a monopoly of violence in the actual enforcement of (property) rights. Our approach is not limited to the discussion of gun control. The more general question is one of self-defense which many state constitutions consider to be an inalienable right, however, with certain restrictions (Volokh, 2007). The law is much more restrictive with regard to self-help actions, such as the private repossession of goods. Under the Uniform Commercial Code, a secured party may, on default, take possession of the collateral without any judicial process; however, this may not cause a "breach of peace" (§ 9-503). Among other examples, on the patent front, Boldrin and Levine (2002) argue that more time and energy seems to be spent on nuisance and defensive patenting of the obvious than on innovation. This is a form of private enforcement of property rights that, according to Boldrin and Levine, is inefficient. Corporations that own digital rights have made huge defensive investments in the past decade that have "provoked an arms race with hackers that continues to escalate" (Bridy, 2009) and even those that favor selfhelp measures regarding digital products have drawn analogies to warfare (Dam, 1999). After enormous investments were made into fighting P2P file-sharing (e.g., Napster) the scene seems not to have changed. The Economist (2008) reports that for every song that is purchased legally, twenty songs are downloaded illegally. Generally, private investments in security exceed public expenditures on the prevention of crime by far (Shavell, 1991). With reference to a Hobbesian state of nature, it has been emphasized that the enormous costs of conflicts come from armament, i.e., a diversion of productive resources to preparing for a potential war; consequently, the nature of a war does not lie in an actual combat

\footnotetext{
${ }^{1}$ For brief overviews, see Mueller, 2003, 380-383, and Dixit, 2004, 138-143.
} 
operation (Kersting, 1996). Is it possible that a monopoly on violence that extends to the actual enforcement of rights which includes a restriction of the individual's ability to self-defend against rights infringements is beneficial from a welfare point of view (and even for rights owners)?

In this paper, we give the idea of a state's monopoly a specific meaning and interpret it not only as a principle that grants the legitimization, but its actual use of force to the state (the 'production' view). In this sense, it establishes an important nexus between the use of force as legitimating concept to a theory that helps to understand better in which fields the execution of its use may not or may be delegated to the individuals. In order to do so, we have to specify the "technological" production of property rights, and we thus borrow from the literature on endogenous property rights that highlights the contest-nature of property-rights enforcement. ${ }^{2}$

From the point of view of efficient property-rights protection, at least two arguments can potentially justify the centralization of enforcement activities (Barzel 2002). First, there may be economies of scale to or public-goods aspects of public enforcement (Tullock 1967, Konrad and Skaperdas 2010), such that, e.g., a police officer who is responsible for an entire neighborhood is preferable to security guards for every individual. Second, private enforcement may have negative externalities, such that, e.g., a private security guard may increase the likelihood of theft on the part of the neighbor (Clotfelter 1978, Polinsky 1980).

We advance a third argument that emphasizes the concurrence of state enforcement and restrictions on private enforcement. The state acts as a commitment device which allows to commit to a certain level of enforcement. ${ }^{3}$ However, commitment will not work

\footnotetext{
${ }^{2}$ For a recent survey of this literature, see Corchón (2007) and Garfinkel and Skaperdas (2007).

${ }^{3}$ Despite its popularity in the social sciences, recent research has shown that commitment on effort levels is a fragile concept. Bagwell (1995) argues that commitment includes an action by a first mover, and the observability of this action for the followers. For sequential games with perfect information, he shows that commitment in the above sense may have no value if the first mover's action cannot be perfectly observed. By contrast, Maggi (1999) argues that commitment has positive value in case players have private information and the follower's strategy is potentially informative. Morgan and Várdy (2007) develop a similar argument to Bagwell's and show that commitment to certain effort levels is impossible if the players face arbitrarily small but positive observation costs and thereby provide a powerful argument in favor of using a protocol where players make simultaneous effort choices. What distinguishes our approach from Bagwell's and Morgan and Várdy's is not so much the model structure but the narrative because the informational content of a signal sent by a Stackelberg-leader "state" is different to the informational content of a signal sent by a Stackelberg leader of otherwise hierarchically indistinguishable players. We think that it is in fact one of the key aspects of the nature of the state that its investments in defense are common knowledge to its citizens and that its actions suffer to a lesser extent from non-observabilities in either the Bagwell or the Morgan and Várdy sense, a fact that enables commitment in the first place.
} 
perfectly if state enforcement is combined with private protection. The reason is that the state will anticipate subsequent private protection, and hence, it cannot commit to an optimal level of enforcement. In order to isolate this effect, we abstract from externalities and economies of scale. For the same reason, we abstract from considerations that support decentralization (self-defense, self-help repossession), such as private information, e.g., with regard to individual preferences, lower costs of private defense technologies, e.g. fleeing, and agency problems, e.g. corruption. Under this framework, i.e. to the extent that considerations of decentralization are negligible, it is optimal for property owners to empower the state with enforcement rights and to waive their individual right to private protection. This results holds for all generic sequential structures of the law-enforcement game between the rights owner and a potential party that infringes with those rights; and it is true even if private protection is non-existent in the first place. The mere possibility of private enforcement suffices for an inefficient protection of rights by the state. The "shadow" of defense has a negative impact on the investments in rights infringements.

An application of the state's monopoly is the prohibition of private armies and mercenaries. Intuitively, the direct damages, e.g., the loss of lives, seems to be an important element for such a prohibition. However, these are not the only costs. Our paper emphasizes the costs of investments in attack and defense and the potential for using these resources in a better way. We will develop the economic intuitions for these results throughout the paper.

Most of the literature has focused on public or private enforcement of rights separately. There is a large body of literature studying aspects of public enforcement of law (see Polinsky and Shavell (2000) for an excellent survey). The basic tradeoff explored by this literature is between the costs of enforcement faced by a government authority and the benefits of enforcement, which depend on the gains from a reduced probability of crime and the type of punishment and the associated costs for the potential criminal. However, it abstracts from the possibility of individuals to engage in private counteractions. On the other hand, the analysis of decentralized rights enforcement (or emergence) has been pioneered in the field of law and economics and public economics by Clotfelter (1978), Polinsky (1980), and Shavell (1991), and in the field of the economics of conflict by Bush and Mayer (1974) and Skaperdas (1992). Closely related is the (law and) economics literature on theft (Tullock, 1967, Posner, 1985, McChesney, 1993, Hasen and McAdams, 1997). Clotfelter (1977) focusses on the interplay between public and private enforcement in a situation when both types of goods and services are imperfect substitutes. This line 
of research, however, does not seek to explain why certain centralized or decentralized activities cannot be replicated at the decentralized (centralized) level in the first place. Grossman (2002) develops a theory of the emergence of the state that is related to our approach. According to his view, a ruling elite can commit to overinvestment in lawenforcement compared to the decentralized solution, which guarantees that no individual decides to become a thief. In contrast, our paper shows that the essential contribution of state production of law enforcement is the necessity to commit to lower expenditures compared to the decentralized level, an observation that may be surprising at first but that is in line with casual observations. Wulf (2004), for example, points out that "[t]he erosion of states and the failure of domestic politics, leading to endemic state weakness and collapse, are conceived by a great number of social scientists as the central cause for war, armed violence and conflict. State collapses give rise to and sustain conflicts, prolong wars and complicate or prevent peace building. The Democratic Republic of Congo and Somalia are used as the classic examples. The most appropriate measure, according to this analysis, is to rectify these deficits by establishing state authority, particularly the state monopoly of force." If there is no deus ex machina that endows a state with a superior technology of defense, the importance of this monopoly must be traced back to some kind of commitment mechanism that allows it to devote less resources to conflict, and this mechanism must be triggered by a joint reduction in arming by both, the defenders and the possible appropriators.

The paper is organized as follows. We introduce the model in Section 2. Sections 3 to 5 are devoted to the derivation and discussion of equilibria under different assumptions about the timing of defensive and appropriative investments. Section 6 concludes.

\section{The Model}

There is a state that formally assigns (property) rights and invests resources in order to enforce them. In spite of enforcement efforts, part of the good protected by a formal (property) right can be misappropriated. Rights owners can invest in additional enforcement. Such enforcement is subject to a contest, where the owner of the right can invest resources that make it more difficult for a person to infringe with those rights (for simplicity we call such a person a thief in the following) and where a potential thief can invest resources 
that increase the (probability of) success of appropriation. ${ }^{4}$

We assume the following two-player contest. The property owner $O$ holds a right $\mathcal{R}$ of value $R$ in a good or resource. In addition, she is endowed with $L$ units of a good $\mathcal{L}$ that is not due to appropriation and that can be used for consumption, $c_{O} \geq 0$, and to defend the formal property right, $d \geq 0, d+c_{O}=L$. We call $d$ the investments in private enforcement of property rights.

Player $T$ is a potential thief. She is endowed with $L$ units of a good $\mathcal{L}$ that is not due to appropriation and that can be used for consumption, $c_{T} \geq 0$, or to appropriate (part of) $\mathcal{R}, a \geq 0, a+c_{T}=L$.

In order to focus on the strategic factors of centralized law enforcement, we analyze a situation where only the property owner can be taxed by the state. This implies that only $\mathcal{L}$ but not $\mathcal{R}$ can be taxed. This convention increases the burden of proof for the case of a monopoly of violence. Including $\mathcal{R}$ in the tax base would have two effects. It would partly shift the tax burden to the thief (which would ceteris paribus be unambiguously preferred by the property owner), and it would reduce the net value of the rent, which would calm down the conflict (which would be a positive side effect of centralized, taxfinanced law enforcement). In addition, we assume that the tax is lump-sum. Restricting tax revenues to come from $\mathcal{L}$ and the lump-sum nature is clearly not intended to be realistic, but eliminates any difference between the property owner and the state other than its strategic role, which is the effect we want to focus on in this paper. To be more specific, a state $C$ can tax $O$ in order to finance investments in the public enforcement of property rights $c \geq 0$. In order to do so, it can use a lump-sum tax $t$ levied on $\mathcal{L}$.

Given this assumption and $c=t, O$ 's budget constraint is modified to $d+c_{O}=L-c$. In addition, the state can regulate the private enforcement of property rights by setting a cap $\bar{d} \geq 0$, such that $d \leq \bar{d}$ has to be respected by $O$. This assumption builds on the intuition that it is easier to regulate investments in the defense of property than in its appropriation. An example would be gun-control laws that have a stronger effect on the ability to carry guns as a defensive measure than on the ability to carry guns as a measure to appropriate property from others (and which is therefore an illegal activity in the first place). Another example would be the prohibition of private armies. All these defensive investments have in common that they are supposed to defend a legal activity that is easier to monitor and control than the illegal activity to appropriate property

\footnotetext{
${ }^{4}$ See Garfinkel and Skaperdas (2007) for a survey of and Denter and Sisak (2010) for a recent important contribution to the contest-theoretic literature on the enforcement of property rights.
} 
rights. Generally, a regulation of investments through taxes could be easier targeted at legal activity. Unlike many who focus on the regulation of appropriative activity, i.e., the activity of the offender, and assumes defensive activity to be unregulated, we emphasize the regulation of defensive activity. Even though the idea of restricting private protection is not completely novel, ${ }^{5}$ the approach has been widely overlooked in the literature.

We assume that the only difference between private and public enforcement of property rights is the ability of the state to commit to a certain investment level $c$. The state is therefore seen as a commitment device that, if credible, allows to overcome certain dilemmas of (simultaneous) decentralized decision-making. ${ }^{6}$ This implies that we make the assumption that $C$ and $O$ have access to the same type of enforcement technology such that their investments are perfect substitutes.

Given a tuple $\{c, d, a\}$, the probability of appropriating (defending) the good $\mathcal{R}$ or the fraction of $\mathcal{R}$ that is successfully appropriated (defended against appropriation) is given by the Tullock contest-success function (Tullock 1980). ${ }^{78}$

$$
p(c, d, a, \theta)=\left\{\begin{array}{cc}
\frac{c+d}{c+d+\theta a}, & c+d+a>0 \\
1, & c+d+a=0
\end{array}\right.
$$

Property rights are secure if $p()=$.1 and insecure if $p()<.1 . \theta$ measures the relative effectiveness of appropriation compared to defense. It reflects the technological aspect of law enforcement. A high value of $\theta$ ceteris paribus implies that it is difficult to deter thieves from stealing which is common for the protection of intellectual property. A low value implies that it is relatively easy to deter thieves from stealing which is typical for

\footnotetext{
${ }^{5}$ See Shavell's brief discussion in his conclusion (Shavell 1991)

${ }^{6}$ See Bowles (2006), Part 1, for a comprehensive discussion. See also Shavell (1991), who assumes that individuals can commit to a certain level of precaution collectively. Following Schelling (1960), the idea of commitment has become popular in the social sciences. The prerequisites for successful delegation are still highly disputed in economic theory. Bagwell (1995) has shown that commitment may have no value if the first mover's action is imperfectly observed, even if the noise is slight. The result is established in a game without asymmetric information about players' types, which implies that the signal to the follower is not informative. Maggi (1999) shows that private information by the leader of a parameter that is not directly relevant to the follower (but indirectly by strategic interdependence) can reestablish the value of commitment because not the signal received by the follower is potentially informative and the leader may make use of this fact.

${ }^{7}$ Together with the perfectly discriminating contest-success function (or all-pay auction), the Tullock function is the most widely accepted workhorse in contest theory. See Garfinkel and Skaperdas (2005) and Konrad (2009) for surveys and Skaperdas (1996) for an axiomatic characterization of this function. For a different approach tailored to gun control, see Donohue and Levitt (1998).

${ }^{8}$ Given that both players are assumed to be risk-neutral, it does not matter whether we give $p($.$) a$ deterministic or a probabilistic interpretation.
} 
real estate because the good is immobile and rights are easy to verify. Both individuals are risk-neutral so that their utility can be represented by the functions

$$
\begin{aligned}
& u_{O}(c, d, a, R, L \theta)=p(c, d, a, \theta) R+L-c-d, \\
& u_{T}(c, d, a, R, L \theta)=(1-p(c, d, a, \theta)) R+L-a .
\end{aligned}
$$

$O$ and $T$ cannot spend more than their endowment, $L-d-c \geq 0$ and $L-a \geq 0$, and we assume that $L$ is sufficient to make sure that the constraints are not binding in equilibrium.

Given that we focus on the state as a commitment device, we assume that it maximizes the utility of $O$ only. This approach reflects the fact that, typically, a state is not concerned with protecting unlawful activity, and - from a theoretical perspective - increases the burden of proof for the case of monopoly of violence. ${ }^{9}$ Also, it allows us to focus on the regulation of defense investments. We also assume that the state can commit to a certain level of investment. This structure portrays a situation where conflicts between property owners and potential thieves take place within an established institutional environment where police and a court system exist already, an assumption that is natural for the questions we have in mind. However, the sequence of moves between owner and thief is unclear and context dependent. There are three generic situations that can be distinguished and that will be analyzed in the paper.

- A simultaneous determination of $d$ and $a$ is a natural assumption in cases like selfdefense and in cases where investments of the other party are not observable when making one's own investments. We analyze this situation using the following game structure: at stage 1 , the state determines a tuple $\{c, \bar{d}\}$. At stage $2, O$ and $T$ simultaneously determine $d$ and $a$.

- A sequential determination of $d$ and $a$ with $O$ moving first is most appropriate in situations where the owner develops and integrates defensive measures into products, which is the case for example with houses (alarm systems, fences, locks). We analyze

\footnotetext{
${ }^{9} \mathrm{~A}$ state that maximizes, for example, a (weighted) sum of agents' utilities could have an incentive to regulate private enforcement in order to redistribute between $O$ and $T$. Using insecure property rights as a means to redistribute between different individuals is a totally different legitimization of a monopoly of violence that raises deep philosophical as well as legal issues that are beyond the scope of this paper. Alternatively, our model could be interpreted as focussing on two different roles (owner and thief) individuals play in different contexts. This interpretation would make it difficult to exclude the utility from illegal activities from individual utility.
} 
this situation using the following game structure: at stage 1, the state determines a tuple $\{c, \bar{d}\}$. At stage $2 O$ sets $d$ and at stage $3 T$ sets $a$.

- A sequential determination of $d$ and $a$ with $T$ moving first seems to be most relevant in cases where property rights have to be established in an environment where potential appropriators have already invested into certain skills or technologies before a single owner can start protecting herself. It also reflects cases like self-help repossession where the property owner seeks to regain his good without court intervention. We analyze this situation using the following game structure: At stage 1, the state determines a tuple $\{c, \bar{d}\}$. At stage $2 T$ sets $a$ and at stage $3 O$ sets $d$.

\section{Simultaneous determination of defensive and offen- sive activities}

We first analyze a world without any regulation on private enforcement $(\bar{d} \rightarrow \infty)$. This approach allows us to understand better the role of a cap on private law enforcement. Solving the game through backward induction yields the following result (as explained in the Appendix), where $e(\theta)=\left(c^{*}(\theta), d^{*}(\theta), a^{*}(\theta)\right)$ is the combination of choices on the equilibrium path:

$$
e(\theta)= \begin{cases}c^{*}=R /(4 \theta), d^{*}=R\left(\theta /(1+\theta)^{2}-1 /(4 \theta)\right), a^{*}=(\theta R) /(1+\theta)^{2} & \text { if } \theta>1 \\ c^{*}=R /(4 \theta), d^{*}=0, a^{*}=R\left(1 / \theta-1 /\left(2 \theta^{2}\right)\right) / 2 & \text { if } 0.5<\theta \leq 1 \\ c^{*}=\theta R, d^{*}=0, a^{*}=0 & \text { if } \theta \leq 0.5\end{cases}
$$

Figure 1 illustrates these findings. If $\theta \leq 0.5$, appropriation is relatively difficult, which implies that public enforcement is sufficient to deter appropriation completely. Deterring appropriation is costless if $\theta=0$ because the thief has no possibility to appropriate successfully. Public enforcement is increasing in $\theta$ because it is becoming increasingly tempting to start appropriation, which implies that the amount of resources that have to be invested to deter appropriation has to become larger the larger $\theta$. At $\theta=0.5$, the regime changes. If $\theta \in(0.5,1]$, appropriation is still relatively difficult, but deterrence is now so expensive that it is better to accept a certain degree of appropriation. Hence, total public investments in appropriation go down again. However, these investments are still sufficient to deter the owner of the good to start investing in the private enforcement of her rights. At $\theta=1$, there is an additional regime change. At this point, appropriation has 


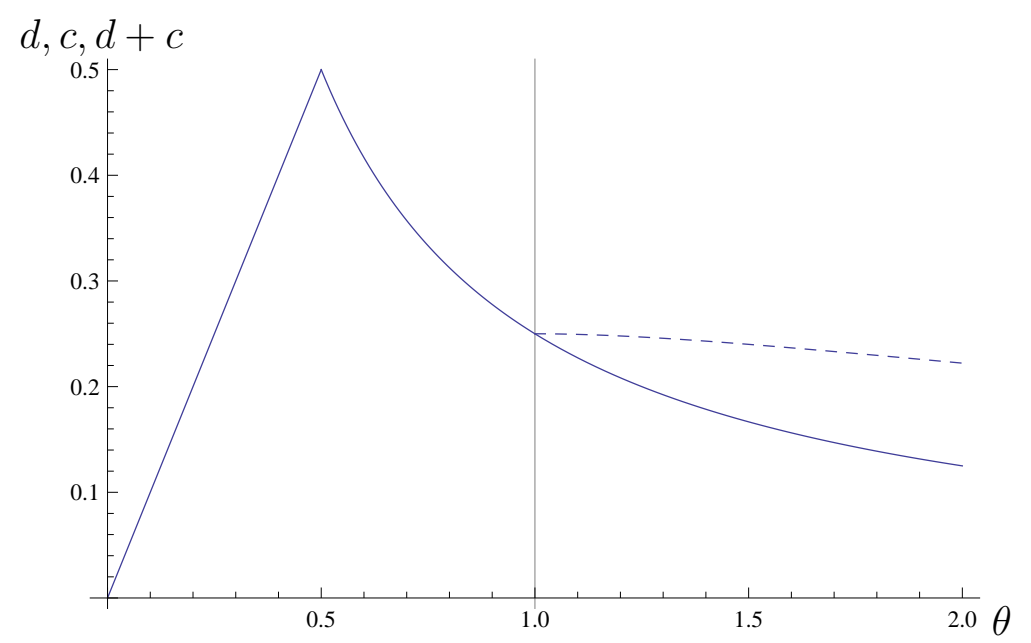

Figure 1: Public and private investment in the enforcement of property rights for different levels of $\theta .(L=1, R=1)$

neither a handicap nor an advantage compared to defense. For $\theta>1$, the solid graph gives the amount of centralized investment in law enforcement. This amount is insufficient to prevent $O$ from engaging in private enforcement activities. The sum of public and private enforcement investments is given by the dashed graph, which shows that the owner would engage in additional enforcement activities (equal to the vertical difference between the upper and lower graph) if this were possible.

What is the economic rationale for this behavior, and how do we evaluate it? The role of the state as a commitment mechanism crucially depends on the relative effectiveness of stealing. If appropriation is relatively difficult compared to defense, the effect of this commitment is that there are secure property rights and exclusively publicly enforced property rights. However, if appropriation is relatively easy, the committed level of law enforcement appears to be insufficient from the point of view of $O$. Hence, she will start investing in private law enforcement. However, the welfare consequences of this increase in private enforcement are negative, even from the point of view of $O$ (who would prefer to commit to zero defense but cannot). This apparently paradoxical conjecture is supported by a comparison in utility levels. In equilibrium, the indirect utility of $O$ in Regime 3 is equal to

$$
V_{O}(\theta, R, L)=\frac{R}{(1+\theta)^{2}}+L
$$


The indirect utility of $O$ in case that she would invest $d=0$, however, would be

$$
V_{O}(\theta, R, L \mid d=0)=R /(4 \theta)+L
$$

which is unambiguously larger in the relevant parameter range. This result allows it to determine immediately the role of a cap $\bar{d}$ on private investments in enforcement.

Proposition 1 . Banning private enforcement, $\bar{d}=0$, increases the utility of the property owner $O$.

Proof. $\Delta_{O}=: V_{O}(\theta, R, L)-V_{O}(\theta, R, L \mid d=0)=-\frac{R}{4}\left(\frac{(1-\theta)^{2}}{\theta(1+\theta)^{2}}\right)<0$.

The reason for this inefficiency is as follows. As far as private enforcement occurs $(\theta>1)$, we are in a situation where $d$ and $a$ are strategic complements, which implies that the state can reduce $a$ by a reduction in total investments $c+d$. This effect, however, is neglected by $O$. The commitment effect of the state is not perfect if it cannot control private enforcement investments by $O$. Hence, the Nash equilibrium of the complete game includes an enforcement monopoly of the state, $\bar{d}=0$. A large $\theta$ represents a fight over digital products and it is exactly in this case that a limitation of defensive investments is suggested in the literature (e.g., Lunney 2001).

It is in the interest of rights owners if their rights are restricted. Individuals will retain their powers if there are economies of scale from private enforcement. For example, the use of violence for matters of self-defense is allowed to the extent that it is necessary. In case of an immediate threat, the state cannot protect an individual, or state protection would require investments that are prohibitively high. Also, it is typically not allowed to use force that is deadly to humans in order to protect property. There is a "duty to retreat" outside one's home instead of using lethal force if retreat is safe (Volokh, 2007).

\section{Sequential determination of defensive and offensive activities, defender moves first}

In this case, $O$ determines $d$ at stage 2 , and $T$ determines $a$ at stage 3 . We are looking for subgame-perfect Nash equilibria of this game. The solution of this game can be trivially deduced from the analysis of the last section because the sequential structure 
of investments implies that $O$ has in fact a commitment device that makes any centralized investments in law enforcement redundant. Both decentralized and centralized investments in law enforcement lead to the same outcome with a continuous number of equilibria $c+d=d *$. Such a neutrality result does not give strong support for a monopoly of violence, but it does not stand in its way either. In this case, the fact that defensive measures, like alarm systems, locks, fences, passwords etc. are not prohibited may be best explained by private information with regard to the value of the property to be protected (Tullock, 1967, Shavell, 1991).

\section{Sequential determination of defensive and offensive activities, offender moves first}

In this case, $T$ determines $a$ at stage 2 , and $O$ determines $d$ at stage 3 . We are looking for subgame-perfect Nash equilibria of this game, and the game is solved by backwards induction, again without any cap first $(\bar{d} \rightarrow \infty)$.

The solution of this game builds on the intuitions developed by Yildirim (2005). Solving $O$ 's stage 3 optimization problem yields the following reaction function:

$$
d(R, L, \theta, a, c)=\max [0, \sqrt{R \theta a}-\theta a-c]
$$

Following Dixit (1987), player $T$ is called favorite if the equilibrium share appropriated exceeds 0.5 in a simultaneous Nash equilibrium and underdog otherwise. Baik and Shogren (1992) and Leininger (1993) analyze contests with endogenous moves and show that both players unanimously want to commit to a sequential structure where the underdog moves first if this is possible. This commitment utilizes the fact that, from the point of view of the underdog, both investments in the contest are strategic substitutes, which implies that he reduces investments relative to the simultaneous game. For the contest-success function employed in this paper, $T$ is the underdog if and only if $\theta<1$ and $O$ is the underdog if and only if $\theta>1$ (Kolmar 2008). For $\theta<1$ the state can create a situation where $T$ (the underdog) moves first by setting $c=0$. In this case, a sequential game results where $a$ is determined before $d$. Denote the resulting investments by $a^{\prime}, d^{\prime}$. If $c$ increases, we know from (6) that $d$ is linearly reduced to $d^{\prime}-c$ until the constraint becomes binding. Up to this point, a shift in the structure of $c+d$ has no influence on $T$ 's choice of $a^{\prime}$, he effectively retains his first-mover position. We therefore get multiple equilibria that share 
the property that $c+d$ and $a$ are constant. For $\theta>1$ the situation is different. An analysis of this situation leads to the following solution.

Lemma 1 . If $\theta \leq 1, c(\theta, R, L)+d(\theta, R, L)=(2-\theta) R \theta / 4, \quad a(\theta, R, L)=R \theta / 4$ is the set of subgame-perfect equilibrium paths. Public and private enforcement are perfect substitutes, there are positive investments in appropriation, and property rights are insecure. If $\theta>1$ the subgame-perfect Nash equilibrium path is $c(\theta, R, L)=(R \theta) /(1+$ $\theta)^{2}, \quad a(\theta, R, L)=(R \theta) /(1+\theta)^{2}, \quad d(\theta, R, L)=0$. There is public but no private enforcement of property rights. Property rights are insecure.

\section{Proof. See Appendix.}

Given the analysis of the last section which has shown that private enforcement of property rights is problematic even for the property owner $O$ if appropriation is a strategic complement to defense, and that this case is fulfilled if and only if $\theta>1$ in a Tullock contest, we can state the following proposition without further proof.

Proposition 2 . Banning private enforcement, $\bar{d}=0$, increases the utility of the property owner $O$ if $\theta>1$ and leaves his utility unchanged if $\theta \leq 1$.

Banning private enforcement is therefore neutral if $T$ is the underdog but plays an important role if $T$ is the favorite. Figure 2 illustrates these findings. The left panel displays
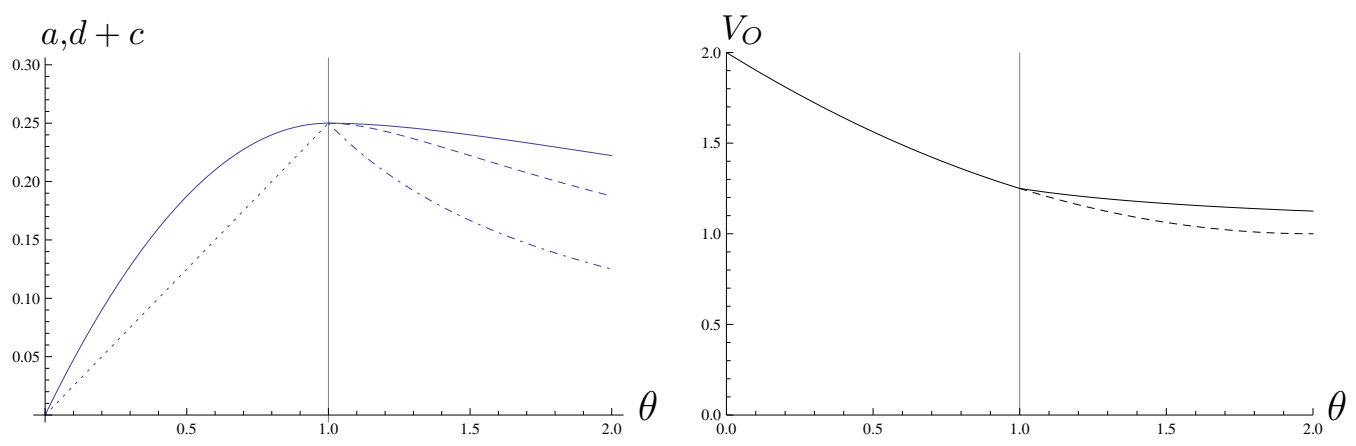

Figure 2: Public and private investment in the enforcement of property rights (left panel) and indirect utility (right panel) for different levels of $\theta$ (sequential $a$ and $d, L=1, R=1$ ).

investments in the contest. For $\theta<1$, the solid graph measures defensive investments $c+d$ as a function of $\theta$, the dotted graph appropriative investments in enforcement. For 
$\theta<1$, the state uses its strategic advantage to delegate the Stackelberg-leader position to $T$ by reducing investments below or up to the Stackelberg-follower investments. This allows a strategic commitment of investments which is profitable for both $O$ and $T$. The scenario changes if $\theta>1$. For larger values of $\theta$, the state would like to use its first move to (under-) commit to certain investments, but is constrained by the incentives of $O$ to invest in private enforcement at stage 3 . The solid graph measures $c+d$ as well as $a$ in case no banning of private enforcement is possible. The dotdashed graph measures $c$ and the dashed graph measures $a$ in case a ban of private enforcement is possible, $\bar{d}=0$. As one can see, banning private enforcement reduces total investments in this contest because it allows the state to use its potential first-mover advantage by reducing investments in $c$. This conjecture is further supported by the right panel of Figure 2 that displays the maximum utility for $O$. The case $\theta<1$ needs no further discussion. If $\theta>1$ the solid line gives the maximum utility of $O$ if private enforcement can be banned and the dashed line gives the maximum utility without any such ban.

This finding looks similar to the one derived for the first model, and the economic mechanism to ban private enforcement in order to be able to commit to reduce investments in the enforcement of property rights is the same. However, from an empirical point of view, both scenarios differ in a very important aspect. In the first model, a ban of private enforcement actually reduces private enforcement investments. In this model, there is no private enforcement in the first place, which implies that a formal ban may appear rather awkward. Nevertheless, a formal ban of private enforcement is necessary for a desirable reduction in public investments in the enforcement of property rights. It is the threat or the 'shadow' of private enforcement that forces the state to overinvest in enforcement.

Our results reflect the fact that self-help in order to repossess a good is widely restricted by the law. Narrow exceptions include the possession of a good by a secured party if the debtor defaults. However, this may not lead to a "breach of peace" (U.C.C. $§ ~ 9-503)$. Typically, the law requires state action to be inadequate, and thus, self-help repossession to be necessary. In MBank El Paso v. Sanchez, the court considered (among other issues) the repossession of a car, where the owner locked herself inside, a breach of peace, hence, the repossession was unlawful. The law seems to require (significant) economies of scale from the private actions. Absent such economies of scale, it makes sense for the property owners to delegate enforcement to the state. 


\section{Concluding Remarks}

We have been able to show that in a situation where the state is interpreted as a commitment device, a ban on private enforcement of property rights is an important feature of optimal state enforcement. Clearly, there are circumstances where private defense is important and to which the right of self-defense applies. However, excluding enforcement activity for which individuals are better suited (private information, lower costs) and abstracting from agency problems, it is optimal for property owners to delegate their enforcement activity to the state completely, even if state enforcement has no economies of scale and there are no negative externalities from individual law-enforcement activities. This result holds for all generic sequential structures of the law-enforcement game. From the state's point of view (and thus from the property owner's point of view), the "threat" of private enforcement is obstructive and it is even useful to prohibit private enforcement activities in a situation where they would not exist at first place.

The private enforcement of rights has been of considerable importance historically, for example in medieval Europe. One of the key factors for the economic success of renaissance Europe had been the development of a code of conduct called the "Lex Mercatoria" in the 11th and 12th century. It helped to overcome the limited possibilities of centralized law enforcement in a politically fragmented Europe. According to Berman (1983), "[t]his legal system's rules were privately produced, privately adjudicated, and privately enforced". This system became effective exactly because medieval Europe was plagued by a maze of fragmented states whose rulers more closely resembled self-interested elites (Berman 1983). To abstract from those agency problems in this paper assumes an environment where property owners have managed to establish a well-functioning state, and our theory is therefore not able to explain the emergence of such a state or the conditions under which it prevails. The reach of our analysis is more limited: if such a well-functioning state exists, we can explain why Weber's concept of a monopoly of violence that is usually interpreted as a principle that locates the legitimization of the use of (physical) violence with the state leverages onto the material investments into (property) rights enforcements. In those states, the use of private armies and mercenaries is prohibited, self-defense measures are regulated, and self-help actions to regain goods without court intervention are widely restricted. From a law-enforcement perspective, it is important to emphasize that the role of the state is not limited to directly regulating criminal activity, but it includes the regulation of victim activity on a fundamental level. 


\section{References}

Bagwell, K. (1995), Commitment and Observability in Games, Games and Economic Behavior 8, 271-280.

Baik, K.H. and Shogren, J.F. (1992), Strategic Behavior in Contests: Comment, American Economic Review (AER), 82(1), 359 - 62.

Barzel, Y. (2002), A Theory of the State: Economic Rights, Legal Rights, and the Scope of the State, Cambridge University Press.

Berman, H.J. (1983), Law and Revolution: The Formation of the Western Legal Tradition. Harvard University Press, Cambridge, Mass..

Boldrin, M., Levine, D. (2002), The Case Against Intellectual Property, American Economic Review 92, 209-212.

Bone, D. (2010), The Heller Promise versus the Heller Reality: Will Statutes Prohibiting the Possession of Firearms by Ex-Felons be Ubheld After Britt v. State?, Journal of Criminal Law and Criminology 100, 1633-1657.

Bowles, S. (2006), Microeconomics: Behavior, Institutions, and Evolution, Princeton University Press.

Bridy, A. (2009), Why Pirates (Still) Won't Behave: Regulating P2P in the Decade after Napster, Rutgers Law Journal 40, 565-612.

Britt v. North Carolina, 681 S.E.2d 320 (N.C. 2009).

Bush, W.C., Mayer, L.S. (1974), Some Implications of Anarchy for the Distribution of Property. Journal of Economic Theory 8 (4), 401-412.

Clotfelter, C.T. (1977), Public Services, Private Substitutes, and the Demand for Protection against Crime. American Economic Review 67, 867-877.

Clotfelter, C.T. (1978), Private Security and the Public Safety. Journal of Urban Economics 5, 388-402.

Corchón, L.C. (2007), The Theory of Contests: A Survey, Review of Economic Design 11, 69-100. 
Dam, K. (1999), Self-Help in the Digital Jungle, Journal of Legal Studies 28, 393-412.

Denter, P., D. Sisak (2010), Imperfect Property Rights: The Role of Heterogeneity and Strategic Uncertainty, University of St. Gallen School of Economics and Political Science Discussion Paper no. 2010-27

District of Columbia v. Heller, United States Supreme Court, 128 S. Ct. 2783 (2008).

Dixit, A. (2004), Lawlessness and Economics, Princton.

Donohue, J. (2004), Guns, Crime, and the Impact of State Right-to-Carry Laws, Fordham Law Review 73, 623-652.

Donohue, J., Levitt, S. (1998), Guns, Violence, and the Efficiency of Illegal Markets, American Economic Review, Papers and Proceedings 88, 463-467.

Garfinkel, M. and Skaperdas, S. (2007), Economics of Conflict: An Overview, in: T. Sandler and K. Hartley (eds.), Handbook of Defense Economics, Vol. II, 2007, 649709.

Grossman, H. (2002), "Make us a King": Anarchy, Predation, and the State, European Journal of Political Economy, 31-46.

Hamblen v. United States, 591 F.3d 471 (6th Cir. 2009).

Hasen, R., McAdams, R (1997), The Surprisngly Complex Case Against Theft, International Review of Law and Economics 17, 367-378.

Hobbes, T., 1642, De cive - On the citizen. Ed. and transl. by Richard Tuck and Michael Silverthorne, 1998, Cambridge.

Hobbes, T., 1651, Leviathan. Ed. by Richard Tuck, 1997, Cambridge.

Holzhauer, H. (1978), Landfrieden II (Landfriedensgesetzgebung), in: Erler, A., Kaufmann, E. (eds.), Handwrterbuch zur deutschen Rechtsgeschichte, Vol. II, 1465-1485. Erich Schmidt Press.

Kolmar, M. (2008), Perfectly Secure Property Rights and Production Inefficiencies in Tullock Contests, Southern Economic Journal, 441-456. 
Kaufmann, E. (1978), Landfrieden I (Landfriedensgesetzgebung), in: Erler, A., Kaufmann, E. (eds.), Handwrterbuch zur deutschen Rechtsgeschichte, Vol. II, 1451-1465. Erich Schmidt Press

Kersting, W. (1996), Die politische Philosophie des Gesellschaftsvertrags, Primus.

Konrad, K.A. (2009), Strategy and Dynamics in Contests, Oxford University Press.

Konrad, K.A. and Skaperdas (2010), The Market for Protection and the Origin of the State, Economic Theory, in print.

Leininger, W. (1993), More Efficient Rent-Seeking, Public Choice, 75, 1993, 43-62.

Levy, R. (2010), Second Amendment Redux: Scrutiny, Incorporation, and the Heller Paradox, Harvard Journal of Law and Public Policy 33, 203-215.

Maggi, G. (1999), The Value of Commitment with Imperfect Observability and Private Information, The RAND Journal of Economics 30, 555-574.

MBank El Paso v. Sanchez, 836 S.W.2d 151 (Tex. 1992).

McChesney, F.S. (1993), Boxed In: Economists and the Benefits of Crime, International Review of Law and Economics 13, 225-231.

McDonald v. City of Chicago, United States Supreme Court, 130 S. Ct. 3020 (2010).

Morgan, J., F. Várdy (2007): The Value of Commitment in Contests and Tournaments when Observation is Costly, Games and Economic Behavior, 326-338.

Mueller, D. (2003), Public Choice III, Cambridge.

People of the State of New York v. Perkins, 880 N.Y.S. 2d 209 (N.Y.A.D. 3 Dept. 2009).

Polinsky, A.M. (1980), Private versus Public Enforcement of Fines. Journal of Legal Studies 9, 105-127.

Polinsky, A.M., Shavell, S. (2000), The Economic theory of Public Enforcement of Law. Journal of Economic Literature 38, 45-76.

Posner, R. (1985), An Economic Analysis of Criminal Law, Columbia Law Review 85, 1193-1231. 
Rosenthal, L., Malcolm, J., McDonald v. Chicago: Which Standard of Scrutiny Should Apply to Gun-Control Laws, Northwestern Law Review 105, 85-113, 2010.

Shavell, S. (1991), Individual Precautions to Prevent Theft: Private versus Socially Optimal Behavior. International Review of Law and Economics 11, 123-132.

Schelling, T.C. (1960), The Strategy of Conflict, Oxford University Press, London.

Skaperdas, S. (1992), Cooperation, Conflict, and Power in the Absence of Property Rights. American Economic Review 82 (4), 720-739.

Skaperdas, S. (1996), Contest Success Functions, Economic Theory 7, 283-290.

The Economist (2008), Internet piracy - Thanks, me hearties - Media firms find that statistics on internet piracy can be rather useful, July 17, 2008, http://www.economist.com/node/11751035.

Tullock, G. (1967), The Welfare Costs of Tariffs, Monopolies and Theft, Western Economic Journal, 5, 224-232.

Tullock, G., 1980, Efficient Rent-Seeking. In: Buchanan, J., Tollison, R., Tullock, G. (eds.), Toward a Theory of the Rent-Seeking Society. Texas A\&M University Press, pp. 3-15.

United States v. Rene, 583 F.3d 8 (1st Cir. 2009).

United States v. Marzzarella, 595 F.Supp.2d 596 (W.D. Pa. 2009).

United States v. Perkins, 526 F.3d 1107 (8th Cir. 2008).

Volokh, E. (2010), Nonlethal Self-Defense, (Almost Entirely) Nonleathal Weapons, and the Rights to Keep and Bear Arms and Defend Life, Stanford Law Review 62, 199-254.

Volokh, E. (2007), State Constitutional Rights of Self-Defense and Defence of Property, Texas Review of Law and Politics 11, 399-418.

Weber, M., 1919. Politics as a Vocation in From Max Weber: Essays in Sociology. Translated and edited by Hans H. Gerth and C. Wright Mills. 1958, New York, Oxford University Press. 
Wimmer, H. (2003), The State's Monopoly on Legitimate Violence. - Violence in History and in Contemporary World Society as Challenges to the State. Paper presented at the Conference "Transformations of Statehood from a European Perspective," Janury 23-25, 2003, Vienna, organized by the Austrian Academy of Sciences.

Wulf, H. (2004), The Bumpy Road to Re-establish a Monopoly of Violence, Paper prepared for Study Group on Europe's Security Capabilities, London School of Economics.

Yildirim, H. (2005), Contests with Multiple Rounds, Games and Economic Behavior, 213-227.

\section{Appendix A: Solution of the game where $O$ and $T$ move simultaneously}

Proof. The second-stage outcome is implicitly defined by the following Kuhn-Tucker conditions:

$$
\begin{aligned}
\frac{\partial u_{O}}{\partial d} & =\frac{\theta a}{(c+d+\theta a)^{2}} R-1 \leq 0 \wedge d \geq 0 \wedge\left(\frac{\theta a}{(c+d+\theta a)^{2}} R-1\right) d=0, \\
\frac{\partial u_{T}}{\partial a} & =\frac{\theta(c+d)}{(c+d+\theta a)^{2}} R-1 \wedge a \geq 0 \wedge\left(\frac{\theta(c+d)}{(c+d+\theta a)^{2}} R-1\right) a=0 .
\end{aligned}
$$

A little algebra reveals that three cases have to be distinguished:

$$
(d(c, R), a(c, R))= \begin{cases}d=\frac{\theta R}{(1+\theta)^{2}}-c, \quad a=\frac{\theta R}{(1+\theta)^{2}} & \text { if } c \leq \theta R /(1+\theta)^{2} \\ d=0, \quad a=\frac{\sqrt{R \theta^{3}(c+d)}-\theta(c+d)}{\theta^{2}} & \text { if } \theta R /(1+\theta)^{2}<c \leq \theta R \\ d=0, a=0 & \text { if } \theta R<c\end{cases}
$$

Inserting these values into $p($.$) reveals that, depending on on the amount of public enforce-$ ment, we may get equilibria where private and public enforcement interact and property rights are uncertain, where there is only public enforcement but still uncertain property rights, and where there is only public enforcement and perfectly secure property rights.

Given the second stage solution, we get the following indirect utility function 
$v_{O}(c, \theta, R, L)$

$$
v_{O}(c, \theta, R, L)=\left\{\begin{array}{cc}
\frac{R}{(1+\theta)^{2}}+L, & c \leq \theta R /(1+\theta)^{2} \\
\sqrt{\frac{R c}{\theta}}+L-c, & \theta R /(1+\theta)^{2}<c \leq \theta R \\
(1-\theta) R+L-c, & \theta R<c
\end{array}\right.
$$

Maximizing (A.4) with respect to $c$ leads to the following solution:

1. If $c \leq \theta R /(1+\theta)^{2}$, the state is indifferent between all levels of $c$ because $c$ and $d$ are perfect substitutes and there is no cost-shifting from $O$ to $T$ with public enforcement. We will use the convention that there is public law enforcement in this case of indifference, $c^{*}=(\theta R) /(1+\theta)^{2}$.

2. If $\theta R /(1+\theta)^{2}<c \leq \theta R$, the first-order condition of $v_{O}$ with respect to $c$ implies that the state would choose $c=R /(4 \theta)$. However, this solution is only consistent with $\theta R /(1+\theta)^{2}<c \leq \theta R$ iff $0.5 \leq \theta \leq 1$.

3. If $\theta R<c$, law enforcement is sufficiently large to deter $T$ from appropriation. The minimum investment that induces $a=0$ is $c=\theta R$. Larger values of $c$ are a waste of resources.

Combining these findings leads to (3).

\section{Appendix B: Technical intuition of Proposition 1}

At stage 2, both players play a simultaneous game. Hence, $O$ does not take into consideration the effect of her choice of $d$ on $a$. This effect is, however, taken into consideration by the state. A small reduction of $d$ at $\left\{c^{*}+d^{*}, a^{*}\right\}$ has the following effect on the utility of $O$ :

$$
\frac{\mathrm{d} V_{O}}{\mathrm{~d} d}=\left(\frac{\partial p\left(c^{*}, d^{*}, a^{*}\right)}{\partial d} R-1\right)+\left(\frac{\partial p\left(c^{*}, d^{*}, a^{*}\right)}{\partial a} \frac{\partial a}{\partial d} R\right)
$$

The first term is equal to zero because of the first-order condition of the stage- 2 optimization problem (we are in an interior solution). The second term depends on $\partial a / \partial d$, which is equal to

$$
-\frac{\frac{\partial^{2} p\left(c^{*}, d^{*}, a^{*}\right)}{\partial a \partial d}}{\frac{\partial^{2} p\left(c^{*}, d^{*}, a^{*}\right)}{\partial a^{2}}}
$$


(Dixit 1987). Hence,

$$
\frac{\mathrm{d} V_{O}}{\mathrm{~d} d}=-\frac{\partial p\left(c^{*}, d^{*}, a^{*}\right)}{\partial a} \frac{\frac{\partial^{2} p\left(c^{*}, d^{*}, a^{*}\right)}{\partial a \partial d}}{\frac{\partial^{2} p\left(c^{*}, d^{*}, a^{*}\right)}{\partial a^{2}}} R .
$$

This leads to the following conclusion, given that $\partial p\left(c^{*}, d^{*}, a^{*}\right) / \partial a<0$ and $\partial^{2} p\left(c^{*}, d^{*}, a^{*}\right) / \partial a^{2}>0$ in a maximum:

$$
\frac{\mathrm{d} V_{O}}{\mathrm{~d} d} \gtreqless 0 \Leftrightarrow \frac{\partial^{2} p\left(c^{*}, d^{*}, a^{*}\right)}{\partial a \partial d} \gtreqless 0
$$

The effect on $a$ that is not internalized by $O$ when choosing $d$ depends on the cross partial derivative of the contest success function: if $d$ and $a$ are strategic complements (positive cross partial derivative), a reduction of $d$ will induce a reduction of $a$, whereas the opposite is true if $d$ and $a$ are strategic substitutes (negative cross partial derivative). For the case of a Tullock function, this effect is unambiguously determined by $\theta$ :

$$
\frac{\partial^{2} p\left(c^{*}, d^{*}, a^{*}\right)}{\partial a \partial d}=\frac{\left(1-\theta^{2}\right)}{\left(R^{2} \theta\right)} \gtreqless 0 \Leftrightarrow \theta \lesseqgtr 1
$$

Hence, we are in a situation where $d$ and $a$ are strategic complements if $\theta>1$, which implies that the state can reduce $a$ by a reduction in total investments $c+d$. This effect, however, is neglected by $O$.

The commitment effect of the state is not perfect if it cannot control private enforcement investments by $O$. This result allows it to immediately determine the role of a cap $\bar{d}$ on private investments in enforcement.

Corollary B.1: Private investments in the enforcement of property rights occur if and only if $\theta>1$. Banning private enforcement increases the utility of $O$ because appropriation is a strategic complement to defense.

Given that private enforcement in property rights plays only a role when $a$ and $d$ are strategic complements, it is always optimal from the point of view of the state to ban private enforcement completely, if this is a viable opportunity. Hence, the Nash equilibrium of the complete game including $\bar{d}$ always has $\bar{d}=0$ as part of the equilibrium strategy of the state. This result holds even though the state is a perfect advocate of the interests of the property owner. 


\section{Appendix C: Proof of Lemma 1}

Proof. For $\theta<1$ the state can create a situation where $T$ (the underdog) moves first by setting $c=0$. An analysis of this situation leads to the following solution:

$$
\begin{aligned}
& c(\theta, R, L)=0, \quad a(\theta, R, L)=\frac{R \theta}{4}, \quad d(\theta, R, L)=(2-\theta) \frac{R \theta}{4}, \\
& V_{O}(\theta, R, L)=R(1-0.5 \theta)^{2}+L, \quad V_{T}(\theta, R, L)=\frac{R \theta}{4}+L .
\end{aligned}
$$

However, for $\theta>1$ the situation is different: $O$ is the underdog, and there is therefore a value of commitment to let her move first. However, such a commitment is not credible in this case because with $\bar{d} \rightarrow \infty$, the owner simply cannot credibly commit not to invest at stage 3. Denote by $d^{\text {sim }}, a^{\text {sim }}$ the equilibrium of a simultaneous two-player contest and by $d^{s e q}, a^{s e q}, c^{s e q}$. We can then show that the equilibrium of the three-stage sequential game is structurally identical to the simultaneous-move Nash equilibrium in the following sense: $c^{s e q}=d^{s i m}, a^{s e q}=a^{s i m}, d^{s e q}=0$. We first prove that this is an equilibrium and then continue to show that it is only subgame-perfect equilibrium.

Given $c^{s e q}=d^{s i m}$ and $a^{s e q}=a^{s i m}$ at the first two stages, it follows from (6) that it is optimal for $O$ to choose $d^{\text {seq }}=0$. Given that the state invested $c^{\text {seq }}=d^{\text {sim }}$ in stage one, investing more than $a^{s e q}=a^{\text {sim }}$ cannot reduce total investments $c+d$ because $c$ is already sunk and $d$ will be zero. So increasing $a$ is never profitable. Reducing investments below $a^{\text {seq }}=a^{\text {sim }}$ can also never be optimal because $T$ is on her reaction function given that $d$ is zero. The state has never an incentive to invest more than $c^{\text {seq }}=d^{\text {sim }}$ because it would like to use its first-mover advantage to commit (the owner is the underdog). If the state invests less than $c^{s e q}=d^{s i m}, T$ would, different to the case where the game ends after this move, increase investments in order to deter $O$ to start investing in the contest: It follows from (6) that $d\left(R, L, \theta, a^{s e q}=a^{s i m}, c^{s e q}=d^{s i m}\right)$ is exactly equal to zero at this point, which implies that for unchanged $a, d$ would be increased one by one with a reduction in $c$, holding the outcome unchanged. However, $\partial d\left(R, L, \theta, a^{s e q}=a^{s i m}, c^{s e q}=d^{s i m}\right) / \partial a<0$, which implies that $T$ can use a reduction in $c$ to improve its position by increasing $a$ ( $T$ is the favorite), which cannot be optimal for $O$. Because both players have a unique optimal strategy in each round, this the unique subgame-perfect equilibrium. Lemma 1 follows immediately. 